\title{
Rescue and rehabilitation of two stray greater one-horned rhinoceros (Rhinoceros unicornis) in Orang National Park, Assam
}

\author{
J. Ahmed ${ }^{1 *}$, S. Sarma ${ }^{2}$ and N. Ahmed ${ }^{3}$ \\ ${ }^{1}$ College of Veterinary Science, Assam Agricultural University, Guwahati - 781 022, Assam, India; \\ ${ }^{2}$ Assam State Zoo cum Botanical Garden, Guwahati - 781 005, Assam, India; ${ }^{3}$ Lakhimpur College \\ of Veterinary Science, Assam Agricultural University, North Lakhimpur - 787 051, Assam, India

\begin{abstract}
Two one-horned rhinoceros were strayed from Orang National Park, Assam and settled in the human habitat area of the Dalgaon circle, Darrang district, Assam. Both the rhinoceros were chemically restrained with 4.9 mg etorphine hydrochloride and $10 \mathrm{mg}$ acepromazine maleate. The animals were medicated with parenteral antibiotic, glucocorticoid, non-steroidal anti-inflammatory drug and antihistaminic. Anaesthetic effect was reversed by diprenorphine at dose rate of $6.5 \mathrm{mg}$ and recovery was satisfactory. Both the rhinoceros were successfully translocated and released near the Magurmari grassland area of Orang National Park, Assam.
\end{abstract}

Key words: Chemical restraining, One-horned rhinoceros, Rehabilitation, Rescue

\section{Highlights}

- Satisfactory rescue operation of two strayed rhinoceros with etorphine and acepromazine.

- Captured rhinoceros were medicated for injuries and subsequent stress.

- Tranquilized rhinoceros were satisfactorily reserved by the administration of diprenorphine.

- Rhinoceros were successfully released in Magurmari grassland area of Orang National Park, Assam.

The greater one-horned rhinoceros (Rhinoceros unicornis) is the only species of rhinoceros found in India. Based on the International Union for Conservation of Nature (IUCN) Red List of Threatened Species 2018, greater one-horned rhinoceros is enlisted under the "vulnerable" species category. This species is presently distributed in a few pockets of southern Nepal, northern West Bengal, Uttar Pradesh, Bihar and the Brahmaputra Valley in Assam. In Assam, large population is found in Kaziranga National Park, Pobitara Wildlife Sanctury, Orang National Park and Manas National Park (Srivastav and Nigam, 2010). Its habitat is surrounded by human dominated landscapes, hence many times rhinoceros strayed out to the human residential areas causing humananimal conflicts. This paper presents successful rescue and rehabilitation of two stray greater onehorned rhinoceros in Orang National Park, Assam.

On $2^{\text {nd }}$ April, 2021, it was reported that two greater one-horned rhinoceros had strayed out from Orang National Park, Assam a week back and moving towards Dalgaon circle of Darrang district, Assam. Both the rhinoceros took shelter in human habitation areas during day time and had been moving continuously ahead towards the national highway 52 during the night.

Forest staffs of Orang National Park were continuously trying to push back the rhinoceros but due to the dense human settlement it was impossible to drive back the rhinoceros to wild, hence it was decided that the rhinoceros would be chemically immobilized and translocated to Orang National Park. 
The first rhinoceros was located inside maize fields in the lateral recumbency position. The rhinoceros was estimated to be 10 to 15 years of age. A $2 \mathrm{~mL}$ metal dart was prepared with $4.9 \mathrm{mg}$ etorphine hydrochloride (Captivon 98; Wildlife Pharmaceuticals) and $10 \mathrm{mg}$ acepromazine maleate (Acepromazine Maleate Injection; Phoenix Pharmaceuticals Incorporated). Broune (Brown) color cartridge was used to fire the dart and projected through Dist-inject N 60 rifle. The dirt had hit the thoracic region of vertebrae and it broke off at the base of needle (cannula). As the animal was not even partially sedated it was decided that second dart would have to be used as the rhinoceros was a threat to the human life and vice versa. Accordingly, the second dart of 2 $\mathrm{mL}$ dart was prepared with a combination of $4.9 \mathrm{mg}$ etorphine hydrochloride (Captivon 98; Wildlife Pharmaceuticals) and $10 \mathrm{mg}$ acepromazine maleate (Acepromazine Maleate Injection; Phoenix Pharmaceuticals Incorporated). The second dart hit the target successfully in the postero-lateral region of the neck. The rhinoceros didn't move much, only 2 meters forward in the maize field. The animal lied in the lateral recumbency position and there was no any reaction after it was poked with a bamboo pole. Hence it was confirmed that the animal was completely sedated. There was no palpebral reflex. The eyes were covered with a green cloth. It was a male. Vital parameters like rectal temperature, heart rate and respiration rate were recorded as $101.6^{\circ} \mathrm{F}, 64$ beats per minute and 14 breaths per minute respectively.

The second rhinoceros also had taken shelter in a maize field like the first one near Beelpar area of Besimari, Dalgoan circle of Darrang district. Accordingly, next day the rhinoceros was located inside a maize field nearby a village. The horn of the animal was pointed and had some wear and tear indicating that it was mature one. Accordingly a dart was prepared with $4.9 \mathrm{mg}$ etorphine hydrochloride (Captivon 98; Wildlife Pharmaceuticals) and 10 $\mathrm{mg}$ acepromazine maleate (Acepromazine Maleate Injection; Phoenix Pharmaceuticals
Incorporated) and projected through Dist-inject $\mathrm{N} 60$ rifle. The dart was fired aiming at the lateral cervical region. However, the dart had bounced off without delivering the drugs after hitting the lateral part of the neck. The second dart was prepared with the same anaesthetic composition and loaded into the tranquilizing gun. The second dart was successfully lodged in the postero-lateral part of the neck. After about 8 minutes, the rhinoceros showed signs of anaesthesia and after 13 minutes after the injection, the rhinoceros lied down though occasionally it raised its head. With the help of a long bamboo pole the ears were poked to confirm the state of sedation. As there was no response, it was confirmed that the animal was completely sedated and safe for approaching. It was blind folded and was examined for any external injuries and wounds. Vital parameters like rectal temperature, heart rate and respiration rate were recorded as $100.4^{\circ} \mathrm{F}, 55$ beats per minute and 12 breaths per minute respectively. It was a male.

On external examination, few minor cuts were noticed in both the rhinoceros. The darts were taken out by using forceps. All the cut injuries including the superficial wounds of the darts were dressed with povidone iodine solution and then herbal skin spray (Topicure; Natural Remedies Pvt. Ltd.) was sprayed. The rhinoceros were medicated with long acting antibiotic enrofloxacin (Flobac SA; Intas Pharmaceuticals Ltd.) @ $2.5 \mathrm{mg} / \mathrm{kg}$ b. wt., gluco corticoid Dexona (Zydus Healthcare Ltd.)@ $60 \mathrm{mg}$ i.m., non-steroidal anti inflammatory drug meloxicam (Melonex; Intas Pharmaceuticals Ltd.) @ $0.1 \mathrm{mg} / \mathrm{kg}$ b.wt. i.m. and antihistaminic drug chlorpheniramine maleate (Anistamin; Intas Pharmaceuticals Ltd.) @ $0.1 \mathrm{mg} / \mathrm{kg}$ b.wt. i.m.

Rhinoceros were placed onto the ramps. After positioning the rhinoceros properly, the JCB vehicle was used to pull the ramp into the cage (Fig. 1) with the help of the belts secured to the ramp. The belts were placed on the digger of the JCB vehicle and it was lifted slowly. 
Indian Journal of Animal Health, December, 2021

\section{Rescue and rehabilitation of one-horned rhinoceros}

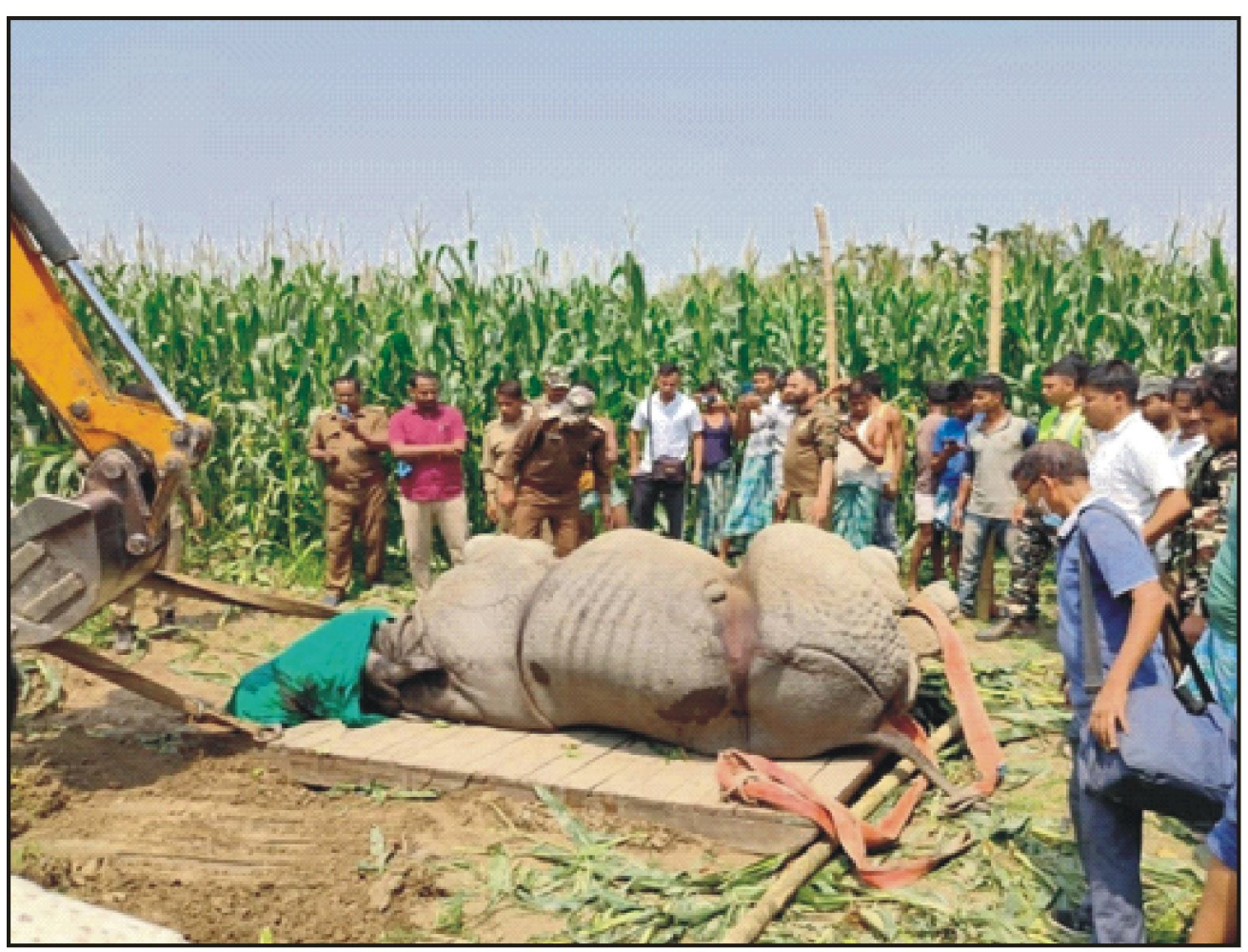

Fig. 1. Pulling of anaesthetized rhinoceros on the ramp



Fig. 2. Release of one-horned rhinoceros in Orang National Park 
Both the rhinoceros were revived by using diprenorphine (Large Animal Revivon; Novartis Animal Health UK Ltd.) @ 6.5 mg i.v. in the ear vein. Both the animals regained its consciousness immediately after the reversal injection and got on their legs in less than a minute. The recovery was smooth.

Both the rhinoceros were successfully released in the Magurmari grassland area of Orang National Park, Assam (Fig. 2).

The occurrence of rhinoceros straying from the protected areas to fringe villages is a common problem encountered by the forest personnel due to various reasons like increase biotic pressure on protected habitats resulting in degradation of the habitat, intra-species conflict, flood etc. (Dutta and Mahanata, 2015). In this paper, chemical restraining with the anaesthetics mixture of etorphine hydrochloride and acepromazine maleate of both the rhinoceros was satisfactory, which was in

\section{REFERENCES}

Ahmed J, Buragohain N, Mekola I, Kyarong S, Choudhury B et al., 2020. First extant record of Royal Bengal Tiger (Panthera tigris) in Dibang valley of Arunachal Pradesh, India with a note on translocation using xylazine and ketamine anaesthesia. J Entomol Zool Stud, 8(2): 531-533

Dutta DK and Mahanta R, 2015. A study on behavior and colonization of translocated greater onehorned rhinos Rhinoceros unicornis (mammalia: Perissodactyla: Rhinocerotidae) during 90 days agreement with the records of Portas (2004). Chemical restraining is frequently used for immobilization and rescue operations of stray wild animals (Ahmed et al., 2020).

Straying out to the fringe areas of human habitat may result in man-animal conflict. Thus, chemical restraining of the animals is a suitable option to capture those strayed animals and translocate to their natural habitat without causing any harm.

Conflict of interest: Authors have no conflict of interest in this study.

Author's contribution: JA: Carried out the rescue, rehabilitation operation, participated in data analysis, draft and revision of the manuscript; SS: Carried out the rescue and rehabilitation operation; NA: Participated in data analysis, draft and revision of the manuscript.

from their release at Manas National Park, Assam India. J Threatened Taxa, 7(2): 6864-6877, doi: 10.11609/JoTT.o4024.6864-77

Portas TJ, 2004. A review of drugs and techniques used for sedation and anaesthesia in captive rhinoceros species. Aust Vet J, 82(9): 542-549, doi: 10.1111/ j.1751-0813.2004.tb11196.x

Srivastav A and Nigam P, 2010. Indian National Studbook of Onehorned Rhinoceros (Rhinoceros unicornis). Wildlife Institute of India, Dehradun and Central Zoo Authority, New Delhi 